\title{
The Existential Doctorate: Liminality in Industry-Academic Doctoral Partnerships
}

\section{Natalie Hardwicke}

Discipline of Business Information Systems

The University of Sydney Business School

Sydney, New South Wales, Australia

\section{Tim Mahlberg}

Discipline of Business Information Systems

The University of Sydney Business School

Sydney, New South Wales, Australia

Email: tim.mahlberg@sydney.edu.au

\section{Kai Riemer}

Discipline of Business Information Systems

The University of Sydney Business School

Sydney, New South Wales, Australia

Email: kai.riemer@sydney.edu.au

\begin{abstract}
Formalised industry-academic doctoral partnerships are increasingly sought as a way to bring academia and industry closer together. However, existing approaches appear to either reinforce the divide between the two "worlds" or acknowledge their independence. By focusing on both the doctoral candidate and their supervisor, we problematise existing doctoral partnership models in order to foreground our own "liminal" and "existential" doctoral experience. We provide self-reflections to discuss how the worlds of industry and academia can be transcended through the "liminal self", as matters of being and belonging are brought into question as the embedded doctoral researcher navigates the two worlds. As a sensemaking process, our paper showcases an innovative and promising approach towards doctoral research; one where the candidate's philosophical contemplation of their identity comes to play an irrevocable role in the exploration of an empirical phenomenon.
\end{abstract}

Keywords Doctoral Research, Industry-Academic, Liminality, Identity, Theory-Practice 


\section{Introduction}

Information Systems (IS) has traditionally been an applied discipline that actively seeks to work with industry and society in the exploration of socio-technical research (Orlikowski and Barley 2001). In Australian universities, we find that expectations of IS scholars to engage meaningfully with industry appear to be increasing. In our own local department these expectations have given rise to an industry co-sponsored scholarship scheme. Naturally, $\mathrm{PhD}$ candidates in this scheme are expected to make contributions to both academia and industry. However, the worldviews held by academic peers in other IS contexts, and of course those of industry colleagues, can often seem "worlds apart", leading to difficulties for the doctoral candidate who is required to navigate the different forms of knowledge embodied by people who comprise each world (Van de Ven 2007).

As two industry-sponsored doctoral candidates, we are writing this paper, with our shared supervisor, as a "confessional account" (Mathiassen and Sandberg 2013) to explore the particular nature of our doctoral projects and experiences which we have come to understand, through reflection and through writing this paper, as the "existential doctorate". While all industry-focused $\mathrm{PhD}$ projects struggle with bridging the divide between theory and practice in their own kinds of ways, the existential doctorate is different in important ways, bridging this divide not merely as a matter of practicality in doing the research, but as a matter of principle in defining the research.

The demarcation of two distinct "worlds", industry and academia, is often discussed in the IS literature in the context of bridging the so-called "theory-practice divide". In this view, the world of industry is often seen as embodying "practice", whilst "theory" is seen as belonging to the world of academia (e.g. Hay 2003; Smith 2006; Klein and Rowe 2008), which leads to tensions and practical problems of translating between these worlds in terms of both language and the particular aims of each. In the following we focus on how scholars have theorised ways in which to bridge the demarcation between the world of academia, and the world of industry, with a view to discuss the role of different kinds of formalised doctoral $(\mathrm{PhD})$ partnerships for doing so.

We will utilise this as a backdrop to discuss the nature, purpose and challenges of the existential doctorate. We will argue that, what sets apart the existential doctorate as exemplified by our own doctoral projects, is that the candidate comes to problematise (Alvesson and Sköldberg 2009) certain assumptions that underpinned their former role in industry. Such problematisation opens a productive space for enquiry, yet necessitates a kind of existential crisis whereby the candidate dwells in a liminal space between worlds, both practically in terms of how the research is organised and in terms of selfunderstanding. We do not purport that this model is in any way better for bringing the two worlds together. We do posit, however, that the most common approaches either reinforce the divide between the two worlds, or at least acknowledge their independence. In our own shared "worldview" however, we take the stance that a clear theory-practice distinction can never be made, as social phenomena are always disclosed through the unity of the two seemingly separate constructs (Feldman and Orlikowski 2011).

We draw upon Van Gennep's (1909) rites of passage, and Turner's view of liminality in such passage stages (1987), to explore how the industry-academic divide can be transcended by focusing on the doctoral candidate themselves, rather than the two worlds. In our own specific contexts, we show that our personal backgrounds have come to play a key role in the liminal experience as we play the roles of both "practitioner" and of "researcher" in iterative engagements across the two world settings. As such, we encounter experiences of belonging within and between both worlds simultaneously. What has emerged for us has been the ambiguous experience of trying to navigate, and make sense of (Weick 1995), the "epistemological chasm" that unfolds in such navigation between industry and academia. Writing this paper is thus itself part of a shared broader sensemaking process, as we attempt to articulate how the identities we assume across the two worlds cannot be divorced from ourselves as individuals, as we try to make overall sense of our respective doctoral research.

Our paper proceeds by first outlining and exploring two common "types" of formalised industryacademic partnership doctoral models that we identified as prevalent in the literature and academic practice. For each, we explore how the two worlds of industry and academia are seen in relation to the candidate and their supervisor, and then contrast these with our own self-reflections. We demonstrate our experiences to-date by taking inspiration from Feldman and Orlikowski's (2011) paper in which the authors offered their own lived experiences of studying practice. In providing reflections of our lived experience to-date, we paint the doctorate as an existential endeavour, as we critically question views of engaged scholarship by outlining how our liminal "self" unifies the two worlds of industry and academia. 


\section{Industry-Academic Partnerships}

Establishing doctoral partnerships as a way to bridge the divide between industry and academia is not new. For example, in our own Australian context, the cooperative research centre (CRC) program was established by the government in the early 1990s for doctoral candidates to become "boundary spanners" across industry, government, and university research bodies (Manathunga et. al 2012). The initiative acknowledged that different forms of knowledge exist in and across localised contexts, and promoted various career opportunities for the doctoral candidates in developing skills across such contexts. Similarly, in some European countries, formalised partnerships have been established from the perspective of doctoral candidates to gain access to more relevant "data", promoting a collaborative research effort for real-world problem solving, and leading to more creative solutions for knowledge exchange between partnered organisations and academia (Borrell-Damian et. al 2010).

We suggest that these industry-partnered research approaches are distinguished from more traditional research that also involves access to industry. A dominant approach would be instances whereby "friendly" industry representatives open their organisation's doors to let the doctoral candidate (and supervisor) "in" for data access, without any expectation of returns in the form of knowledge or learning. For the purposes of this paper, we are staying within the context of formalised partnerships where there is genuine interest and active involvement from parties on both sides. This can often include industry contributions towards some form of doctoral stipend, but will more importantly involve regular interaction throughout the candidature, such as joint decision making for research direction, progress meetings, and ongoing communication as the research unfolds.

We focus on formalised doctoral partnerships for three reasons. Firstly, our own partnerships were established as part of our university's strategy to foster research interaction with industry partners more generally. Secondly, the overall goal of a doctoral thesis is a novel contribution to knowledge, grounded in the rigour of academic methods and theory. In industry partnerships, this creation of knowledge is arguably shaped not only by the candidate's previous status as a practitioner or student, but also in their situated partnership context. Lastly, doctoral programs highlight the candidate in the context of their probationary status as scholars. This, we suggest, is amplified in industry-academic partnerships, as such models are not always developed, or chosen, by the candidate for the aim of creating a purely academic career at the outset.

\section{Common Approaches to Doctoral Partnerships}

In exploring different doctoral models, our search and analysis of the literature proceeded with the aim to identify industry-academic partnerships that were similar, but also distinctly different, from our own. A key element in our literature approach was to look at the problematization of research questions (Boell and Cecez-Kecmanovic 2014), which in formalised contexts draws attention to the empirical "problem" the candidate is looking to address from either an industry or academic perspective. The purpose of engaging with the literature in this manner has been to uncover how the doctoral candidate is perceived across different doctoral contexts within both business schools and universities more broadly. The nature of the two "worlds" that comprise the partnership not only highlights the purpose behind the research, but also how the candidate may approach, and perceive, the divide.

We do not purport to present a complete list of partnered industry-academic cases, past or present. Rather, for the purpose of this paper, we provide three primary partnership approaches that we uncovered in our search. Note that we will for each provide a stylized account that is not intended to describe accurately how such a "model" would be enacted in practice in particular cases. We suggest that the first two general approaches reinforce the divide existing between industry and academia, whereas the alternative third model actively attempts to bridge this divide. We will problematize this third model to foreground our own approach of the "liminal" doctorate as unifying the two worlds.

\subsection{The Industry Problem-Solving Doctorate}

The first model of industry partnered doctoral research we uncovered begins with a motivated industry representative reaching out to a university to "commission" research around a problem they wish to solve (e.g. Roberts 2018). In our own university, there are several partnered scholarships of this variety. An industry partner grants the selected doctoral candidate access to their organisational data specifically to solve a defined problem. As a result, the problem itself appears "pre-packaged" and determined prior to the candidate being selected. The candidate is expected to use the industry data and draw on academic theory in order to support an empirical approach towards solving the industry partner's problem. 
In turn, the research outcome is intended to contribute back to the academic literature. This view of industry-driven problem solving seems to somewhat mirror the established approach of theory "gapfilling" we find commonly in the literature and in general doctoral research approaches; whereby knowledge is missing, and data is collected, analysed, and subsequently used to address this gap (e.g. Westphal and Khanna 2003).

In such a model, however, minimal attention appears to be given to the particular candidate's background in industry, or their own desires for research. The doctoral candidate rather serves as an "academic instrument", suggesting that their role is mostly viewed in terms of their academic research skills rather than any particular industry knowledge. The candidate predominately stays within the academic world and engages with industry at arms-length for data collection purposes, and the sharing of the eventual solution.

The role of the supervisor is mainly to guide and monitor, ensuring the candidate is approaching the industry problem from established theories and research methodologies. Importantly, if we removed the candidate, the research could arguably still be done by the supervisor. This approach could be considered as a typical form of industry problem-solving, with the additional by-product of academic training, in that the candidate is enrolled into the practice by standing in for and being mentored by the senior researcher.

\subsection{The Practitioner-Doctorate}

The second model sees a practitioner who works in industry approach a university to undertake a doctorate, often on a part-time basis. Termed the practitioner-doctorate, this approach has grown in popularity in both the UK and Australia since the early 2000s (Lester 2004) and is set up with the aim to develop the candidate as a "scholarly professional" rather than an academic researcher (e.g. Stewart and Chen 2009). Here, the doctoral research appears secondary in focus as priority is given to the practitioner's primary work role. In some universities this model has been institutionalised as a Doctor in Business Administration (DBA).

In this model, the doctoral candidate is predominately situated in industry and engages with academia in direct response to their practitioner context. The appeal of such a model for academia is that the candidate addresses a "wicked problem" they have identified or are currently experiencing. The engagement with academia may be viewed as legitimising a practice-driven framework that the candidate is trying to establish through scholarship. As such, the model draws on the theory and rigour of methodologies developed in academia for engaging in highly-specialised practitioner contexts; ones which require a research element. Hence, the focus is on the application of certain techniques, rather than specifically on a contribution to academic theory, which may be of lower priority or even the provenance of the doctoral supervisor.

The role of the supervisor is thus quite different compared to the first model. The doctoral research only exists because of the expertise that the practitioner brings to the process. Although the industry context that the candidate is situated in can also be explored by the supervisor, the expertise of the candidate cannot be replicated. As such, the supervisor has to learn and make sense of aspects of the practitionersituated context in order to advise the candidate on relevant theories and methodological approaches. This also brings into question how the supervisor would perceive such a relationship, as the academic contribution is seen as secondary to the industry one.

\subsection{Critical Appraisal of the Two Models}

Both the industry problem-solving and practitioner-doctoral models reinforce the notion of a divide between industry and academia. This is because in both cases, the doctoral candidate is situated firmly within one world while their relationship with the other world is predominantly transactional. In the first case, industry provides a problem for the application of academic theory and research methodology, solved by the doctoral candidate; whilst in the second case, academia provides theory and research methodology for the doctoral candidate to use in their own practical problem. In both cases, one world defines the project by utilising aspects of the other world, and the candidate is regarded as either an instrument or an instigator for bringing the two worlds together.

Importantly, the doctoral candidate in each instance will draw their sense of identity firmly from the context of one respective "world". The industry problem-solving doctoral candidate remains in and of the world of academia, with their identity firmly as that of an academic apprentice who belongs to, and aims to graduate, into the university ranks. The practitioner-doctoral candidate remains in and of the world of industry as a professional, borrowing the academic processes and references of theory in order 
to further their industry-based career. Neither doctoral candidate is truly bridging nor living-in both worlds, and as such can be viewed as reinforcing the industry-academia divide.

\subsection{The Engaged Doctorate}

Unlike in the first two models, an engaged doctorate aims for a more "open door" policy between the worlds of academia and industry. The doctoral candidate is able, metaphorically speaking, to walk backand-forth across the bridge between worlds, because the engaged model requires in-situ involvement of the candidate within and across both worlds. This can be from the perspective of a doctoral candidate currently working as a practitioner, but who is able to "come-and-go" within the academic context, meaning they can engage with different people who comprise each respective world, as well as split their time and physically work out of each world in iterative encounters (e.g. Mathiassen and Sandberg 2013). This approach is also evident from the other perspective, in which the doctoral candidate is seen as having prior industry expertise, and who can also come-and-go within an industry context under the guise of functioning as or like a practitioner (e.g. Cater-Steel et. al 2017).

Although the engaged doctorate model still has the candidate as being situated in one world more than the other, the "coming-and-going" (Nicolini 2012) relationship allows for the exploration of an empirical problem to be identified and then solved, rather than it being pre-packaged as we outlined for the first two models. The idea is that the iterative movement across the two worlds allows the candidate to be a "learner-in-context", rather than as an instrument or a vehicle for required problem solving of a prepackaged empirical topic.

Mathiassen and Sandberg (2013), for example, report on a case in which the industry expertise of the doctoral candidate interacted with their supervisor who served as an active mentor. The candidate experienced frustrations and difficulties in navigating both worlds, as the mentoring role of the supervisor, combined with the role of theory, came to be applied when the practitioner was re-situated back in their industry context. As a result, the candidate made a pragmatic attempt to bridge the knowledge divide between the two worlds.

Outlining another set of examples, Cater-Steel et. al (2017) reported on doctoral candidates engaging in design-science and action research studies, where the candidates worked closely with industry practitioners attempting to solve a problem, which in turn shaped the iterative engagement the candidates needed to have with academia, such as the exploration of existing theories, as well as actively working to explore and solve the industry problem.

\subsection{Critical Appraisal of the Engaged Doctorate}

Although the engaged doctoral model is arguably a more promising way that aims to address the industry-academic divide, it treats bridging of the two worlds as a practical matter. Firstly, doctoral programs themselves are generally set up as a pathway or an apprenticeship process into academia. Much like the first two models, the engaged doctorate still firmly positions the candidate as developing a career in the world they are predominately situated in from the outset. Secondly, there is generally still an expectation, on the industry side, that a concrete problem will be solved by the candidate; the only difference being that the candidate plays a more active role in shaping and solving such a problem through their interactive and iterative engagement across both worlds.

Lastly, the two worlds are seen as "bridged" mostly due to the outcome of the research that ideally benefits both worlds through the iterative process. The existence of the divide between the two worlds is generally acknowledged as an important issue or "wicked problem" to be addressed, which has implications for the experience of the doctoral researcher themselves, who acts as the "boundary spanner" between worlds. What we suggest is missing, however, is a recognition of the emerging other "world" which is shaped through this research approach - that experienced by the doctoral candidate who performs the iterative shifting between worlds, which importantly shapes the research process.

The three approaches we have discussed focus on the doctoral candidate in relation to the two worlds of industry and academia. However, each model downplays, or at worst neglects, the fundamental and essential role of the doctoral candidate themselves; the very individual, we argue, who is not only responsible for bringing the two worlds together through the doctoral research process, but who is the irrevocable element for any sort of "bridge crossing" or "unification" to occur. We will now explore how our own experiences as "embedded" doctoral candidates can be considered as a particular kind of engaged scholarship, and how our approach of being situated in both worlds simultaneously, rather than merely interacting between worlds, allows us to transcend the industry-academic dichotomy, as well as identify and explore unique empirical phenomena which directly depends on the liminal existence on the boundary between both worlds. 


\section{The Existential Doctorate: Our Stories}

Our respective doctoral research approaches build on the engaged scholarship model in that we find ourselves in the iterative space of "coming-and-going" between two worlds, yet in a way that we both experience as "living-in" both worlds. Importantly, in our approach we foreground the doctoral candidate and our experience and journey as being key to the research. We are each sponsored by separate professional consultancy firms and are both situated in the discipline of Business Information Systems at the University of Sydney Business School. While our supervisor and third author established both scholarships with our respective industry partners, we have each been free to explore a social phenomenon of our choosing, so long as it relates to the respective topic areas around the digital workplace and disruptive technologies, such as enterprise social networking (ESN), which is of interest to both industry partners. What we have each chosen to explore, and how, has been premised by the "why" behind our doctoral research and our own backgrounds prior to embarking on the research.

Unlike the other models, which firm up career perspectives at the outset or aim to solve an industry problem, we have engaged in our research from a personal perspective of wanting to explore research issues that are, in important ways, quite personal. Furthermore, and unlike with the other models, there was no immediate expectation on us to deliver a concrete "solution" to our industry partner at the completion of our dissertation, despite the fact that both scholarships include a formalised financial contribution from the industry partners. The reason for this, in one of our contexts, is because the candidate already contributes to theindustry practice each time they are engaged with them. In the other context, the partner seeks to have a formal academic relationship to strengthen their consultancy bravado and interest in research. The main way each of our partners can benefit from our research is by learning and self-reflecting on their own practices, as told through our eyes. In the following we discuss our own respective stories, taking cue from Feldman and Orlikowski (2011). We then explore how our identities have come to play a key role in our doctoral approach in transcending the divide.

\subsection{Natalie's Story}

My PhD was advertised as an industry-partnered scholarship exploring ESN. I had built my career as a business analyst, but at the time of seeing the advertisement, had been employed as an internal communications (IC) manager; someone responsible for implementing and managing social "channels", such as ESN, inside a workplace context. I was also in the process of completing my part-time master's thesis exploring how ESN was changing the theory and practice of the IC function. I had also published industry book chapters about how IC teams can still achieve their objectives of top-down communication, and promoting employee engagement, despite ESN putting power in the hands of endusers. My work and master's research focused on ESN in reference to the needs of IC. However, in order to commence my $\mathrm{PhD}$, my prior industry work had to be given up.

From week one of my $\mathrm{PhD}$, I began accompanying my scholarship company, Ripple Effect Group (REG) under the guise of being one of their practitioners. REG are a small consultancy group specialising in design thinking approaches towards the digital workplace; specifically, designing solutions for how social technology can be introduced and used by employees inside the workplace. I knewvery little about their working practice, so had to learn "on the job", which I later discovered was part of their approach to design, of taking people on a journey of "doing". I would attend their client meetings as a practitioner, and would later ask the team members questions, as a researcher, about what we had experienced. I would then go to my supervisor to discuss both of these contexts, who would then suggest literature for me to read. At the same time, I also had coursework and teaching commitments within the academic context. My time across both world settings has had this even split throughout my candidature.

Within the first two months of my dual practitioner-researcher role, I noticed a pattern. All of REG's clients were coming from an enabling business function, just like the one that I myself had worked in prior, such as IC, and they all wanted to impose social technology onto their employees, much like what my previous industry role had required and what my master's thesis explored. However, the client worldview of the people-technology relationship was distinctly different to that of my scholarship company (and that of my supervisor). As a result, conflicts and tensions between client and consultant emerged (see Hardwicke 2017). I knew I wanted this to be the topic of my $\mathrm{PhD}$ research around the sixmonth stage, as this was when I experienced a kind of existential crisis. I had realised that my prior "self" had sensitised me towards this phenomenon, but in order for me to explore it empirically, I had to unlearn everything I thought I knew about technology and the IC function. This was not easy, as it meant re-evaluating my entire industry career, and renouncing the contribution of my master's thesis. But at the same time this insight and existential struggle was what allowed me to problematize in effective ways 
the approach to technology implementation embodied by the IC function (and much of the IS literature), and by my prior self.

\subsection{Tim's Story}

Prior to starting my doctoral studies, I worked in a large Australian financial services organisation. My earlier roles leveraged my postgraduate masters in organisational psychology in a more traditional way as an internal consultant. However, over several years of job transitions, I'd found myself working in a unique role that would be considered quite innovative and on the "fringes" of a typical career in this industry. Always intending to do further study, but not knowing exactly what area in, I was alerted to my doctorate opportunity through a social media post by a colleague. The broad focus of the topic, "exploring the future of work", appealed to me both in its relevance to my own recent experience, and the ability for me to shape my research direction. It was an industry conversation that I wanted to contribute meaningfully to, and which I currently do outside of my doctorate through independent consulting work, drawing on both my previous experience and increasingly my doctoral research.

In the first year of my candidature, I spent a lot of time in the offices of my sponsoring organisation, a global professional services firm, informally interviewing individuals and attending events which seemed relevant to my broad research area. Over time, I noticed a distinct pattern in the individuals I met there which I found most interesting; they were helping the firm to adapt and evolve by performing knowledge work that went above and beyond their formal role in the organisation, and they often used social media to facilitate this. From this observation, I've drawn on identity theory to conceptualise this alternative knowledge work as the performance of an "alter-identity", whereby multiple professional identities are lived simultaneously (Mahlberg 2017).

Importantly, this phenomenon, now central to my doctoral thesis, both reflects my earlier career working in the financial services firm, and my concurrent consulting work where I act as a "catalyst" operating on the "fringes" of my client organisation in order to sense-make new directions, drive innovation, and design new services. In this way my research traces my own story, which is the very reason that I was attuned to see this phenomenon. Most recently, I reflected on this as I completed a number of in-depth interviews with employees from my sponsoring company, professing to my coauthor colleague that "I feel like I have been interviewing myself".

It is a strange experience to simultaneously identify with my interviewee and "belong", but also be on the outsidelooking into their world as a researcher. I could say the same for "being" a doctoral candidate, as I regularly reflect on both belonging (as a doctoral candidate) and not-belonging (as a practitionerconsultant) in the academic world, as I perform other various identities around the university, including those of mentor and teacher. It is quite befitting that my emerging research direction has sensitised me not only to the multiple identities I performed in my work prior to the doctorate, but also now across different contexts, and how it has challenged my prior convictions and worldview as an organisational psychologist, in ways that has allowed me to see the unique nature of the alter-identity phenomenon.

\section{Discussion}

In comparison to the doctoral partnership models outlined earlier, we suggest three specific areas in which our "embedded" doctorate approach offers unique extensions: the role and identity of the researcher, the liminal nature of our research process, and the changing role of the supervisor. We explore each of these through our preliminary shared sensemaking of our research journeys, and outline what this allows us to do differently compared to the other models.

\subsection{Identity: Matters of Being}

In both our cases, our identities and sense of belonging play a central role in our research. Instead of being merely "engaged" doctoral candidates, we are "embedded" and "invested" within both worlds. What appears in each case is a performance of multiple identities within each world, whereby the identity of both practitioner and researcher is performed with the partnership company, depending on the context. Similarly, on the academic side, identities of doctoral candidate, coursework student, mentor or teacher are performed, depending on the context. Performing multiple identities has sensitised us, as individuals, to a "meta" view of ourselves; whereby our "moving between" identities and contexts leads to a questioning of where we belong as we make sense of our overall doctoral experience (Weick 1995).

This "meta-identity" is also being performed by each of us as we conceptualise and write this very paper. This shared experience has emerged organically over time, leading us to not only forge an "alliance" with 
one another in our sensemaking, but to recognise a supplementary phenomenon in addition to our primary empirical one; the contemplation of the "self" in the epistemological "chasm". In other words, iterations of coming-and-going between industry and academic worlds mean that our experience within one world shapes the experience we come to have in the other world, though we do not identify as belonging in one world more so than the other. Instead, the coming-and-going changes the "self" who navigates between, rather than the navigation bringing the two worlds together. The changing self becomes the metaphorical bridge. Although the self remains the "constant" across such navigation, it is the changing self which enables each world to "converse" and create meaning with the other.

Our shared sensemaking alliance formed through our observation that both of us feel we are investigating an aspect of our prior industry "selves" through our empirical research, and thus also problematising the professions we held before embarking upon our doctoral studies. This has been augmented by the relationship with our supervisor who has challenged us to rethink what it means to "be" in the world in the first place (Dreyfus and Wrathall 2005). In turn, we have not only come to question our prior practitioner identities, but also our prior academic identities, which were based on different ontological paradigms compared to our current doctoral studies. We suggest that this is a unique feature and existential challenge that has arisen from our "embedded" doctoral research approach, which led us to coin the term "existential doctorate".

What is not shared in our stories above is the lived experience of this coming-and-going between worlds; the tensions and frustrations, the emotions behind identity breakdowns, and the existential crises that this experience gives rise to. Ironically, these experiences are what we have also come to document in our empirical research as we encounter our respective phenomenon in the context of our partnered organisations. Exploring this is beyond the scope of this paper, but a promising, albeit deeply philosophical direction, to which we wish to take our enquiry further.

Importantly, we hope to highlight that the role of identity in our doctoral research becomes more personal and therefore more demanding; requiring significant "identity work" (Alvesson \& Wilmott 2001). Our model goes beyond just drawing on the prior professional expertise of the candidate, as expected in the practitioner-doctorate approach, but brings the individual more intimately into the topic and phenomenon of investigation, in that the research is shaped through the individual.

Furthermore, we argue that the research phenomenon is identified because of the individual and their unique worldview that forms from being and going in-between worlds. The "whole" individual becomes the interpretive tool in the research process; the self who is being sensitised and recalibrated in iterative engagements in the context of exploring an organisational phenomenon. This makes our experiences distinctly different from other partnership approaches.

\subsection{Liminality: Matters of Belonging}

For the purposes of this paper in exploring questions of self, identity and belonging between worlds, we found it useful to draw on Van Gennep's rites of passage (1909) and Turner's (1987) view of liminality. Van Gennep suggests three rites of passage before individuals are accepted into, and belong to, any social practice. Until such passage is achieved, an individual remains "on probation". In the first stage, an individual must abandon their prior identity and navigate the unfamiliar territory of the community they seek to join. In the second stage, the individual experiences a sense of transition - of no longer identifying themselves with their previous community, yet still not being fully included in the new community. In the final stage, an individual completes their probation and becomes a community member.

In our doctoral contexts, we see ourselves in the second stage of being in-transition. We haveabandoned our previous practitioner "selves", but do not currently hold status or belonging in either world that comprises our respective industry-academic contexts. The role of liminality, in this second stage, is our lived experience of being "betwixt and between" these two worlds (Turner 1987). We experience "encounters" of belonging as we navigate the two worlds in iterative engagements.

In our cases, the liminal engagement of being planted in both worlds simultaneously, but not being a full community member of either, means the destination at the outset of our doctoral degree is not clear. Unlike the previously discussed approaches, we do not belong in, nor identity ourselves as being in, one world more so than the other world. However, we argue that to not identify or belong in either world is a strength of the "liminal doctorate" experience. In exploring our phenomenon from a stance of ontological inseparability (Riemer and Johnston 2017) in which we cannot divorce ourselves from navigating the two worlds, our empirical phenomena becomes explored via the "holistic self" in the ambiguous in-between space. 
Thus, being embedded in both worlds, but belonging to neither, means that our liminal experience allows us to explore an empirical phenomenon that would not otherwise be possible. It is only through such liminal engagement in which our sense of identity has played a key role, that a Gestalt shift has been able to take place. In both of our examples, our prior practitioner selves foregrounded our respective empirical phenomenon. However, in no longer identifying in that role, and nownot belonging as members in either of our current industry-academic contexts, our identity breakdown has become the instigator of this Gestalt shift. The "break" with the former self is what has allowed for an intellectual "opening" for our respective research to take shape.

Through this break we have been able, as researchers, to be outsiders looking-in to the practices we once identified with (as practitioners), but for which we had not previously been sensitised to as we are now. As we were once on the "inside" of these practices, our passing through the first rite of passage stage is what has allowed for an "outsider" contemplation that we employ in our current second passage stage. Previously familiar aspects of this practitioner world have now come into focus as strange because we now have experience of being outside, yet we are nevertheless able to draw on the intimate knowledge of having once been part of it, which was the very basis for doing the research.

In sum, the liminal journey of simultaneously navigating the old and new worlds is what gives rise to the contemplative self; one who takes a "middle-way" between two worlds and existentially questions themselves in the process of such a journey. This makes for a productive opening for critically reflecting and thus carrying out the research about the former world, without having been restricted by becoming fully part of the new one. Although beyond the scope of this paper, this view of the self as being the unifying element for the bridging of two perceived worlds is a central tenet of the Chinese philosophical notion of yin-and-yang, whereby the ' $S$ ' line between the two parts of the black-and-white symbol is regarded as the middle path - the route an individual takes for harmonising opposite states (Chen 2002).

\subsection{Role of the Supervisor: Matters of Existential Questioning}

Finally, we suggest that our "embedded" doctorate calls for a different role of the supervisor. Given that there is greater entanglement between the individual's identity(s), experiences and the emerging research topic, the supervisor is required to be more involved in a sensemaking capacity than might be expected in other partnership doctorates where advice concentrates more on process and methods. This is partly due to the absence of clearly expected research outcomes provided from the outset that comes from either academia or industry in the other models, but also because of the more "wicked", and indeed existential problems that may be tackled through the existential doctorate.

Our approach also acknowledges that the thesis topic is intimately entangled with and in reference to both worlds, even though the supervisor is situated in the academic world. As such, the personal nature of the doctorate experience requires greater sensitivity from the supervisor to the existential line of enquiry that will emerge. The identity of the supervisor and their prior involvement with industry partners may also play a key role. In our case, our supervisor had an academic relationship working with both of our industry partners prior to our doctoral commencement, which was essential for securing the openness of the industry partner which we suggest was critical to enable our embedded, liminal study. Therefore, the supervisor's role is required to go beyond that of a custodian of the rites of passage of the academic world, to that of "philosopher-guide", supporting the candidate to uncover knowledge and truths which are meaningful for them, as well as being open to exploring new aspects of the industry partner they had prior engagement with.

Importantly, the supervisor must see the researcher as more than merely incidental to the research process, but rather central to it, and respect the iterative nature of open self-discovery over the course of the research process as this is key to making sense of the research topic at hand. We argue that this also requires a different epistemological understanding of how knowledge is created, and ontological appreciation for the lived experience of the doctoral candidate. Further inquiry into the supervisor relationship in the liminal doctoral experience seems promising, especially given the observation that in our particular context, where we have shared the same liminal phenomenon, we have also shared the same supervisor.

\section{Conclusion}

What we have foregrounded in this paper is an innovative, novel approach to doctoral research in formalised industry-academic partnership contexts. By taking a more embedded approach and focusing on the individual doctoral candidate, we have explored how existential questions of performing multiples identities across, within and between the worlds of industry and academia can help in the 
uncovering and exploration of a novel organisational phenomenon. The focus on the doctoral candidate not belonging within either world allows for transcendence of industry and academic worlds through an experience of liminality; of unlearning one's prior identity, and not belonging in either side of an industry-academic partnership. As the writing of this paper has in itself been a sensemaking activity for ourselves, we have used the process to explore the "meta" identity aspects of our respective doctoral journeys. We want to keep exploring and elaborating on the ideas expressed in this paper in a future publication, as this paper forms part of our initial (public) sensemaking process.

\section{References}

Alvesson, M., and Sköldberg, K. 2009. Reflexive Methodology: New Vistas for Qualitative Research (Second Edition). London: Sage Publications Inc.

Alvesson, M., and Willmott, H. 2001. "Identity Regulation as Organizational Control : Producing the Appropriate Individual," pp. 1- 32.

Boell, S.K. and Cecez-Kecmanovic, D. 2014. "A hermeneutic approach for conducting literature reviews and literature searches," CAIS, 34, p.12.

Borrell-Damian, L., Brown, T., Dearing, A., Font, J. and Hagen, S. 2010. "Collaborative doctoral education: University-industry partnerships for enhancing knowledge exchange," Higher education policy, vol. 23, no. 4, pp. 514;493;-514.

Cater-Steel, A., Toleman, M. and Rajaeian, M.M. 2017. "An analysis of design science research adoption in Doctoral projects in Australia", In Proceedings of the 28th Australasian Conference on Information Systems (ACIS 2017), Australian Association for Information Systems.

Chen, M. 2002. "Transcending paradox: The Chinese "middle way" perspective," Asia Pacific J ournal of Management, 19 (2-3), pp.179-199.

Dreyfus, H. and Wrathall, M. 2005. "Martin Heidegger: An introduction to his thought, work, and life," A companion to Heidegger, pp.1-15.

Feldman, M. S. and Orlikowski, W. J. 2011. "Theorizing Practice and Practicing Theory," Organization Science (22:5), pp. 1240- 1253.

Hardwicke, N. 2017. "Practices in J uxtaposition: Tensions in social software appropriation projects”, in Proceedings of the 28th Australasian Conference on Information Systems (ACIS 2017), Australasian Association for Information Systems, Hobart.

Hay, G.W. 2003. “Executive PhDs as a solution to the perceived relevance gap between theory and practice: a framework of theory-practice linkages for the study of the executive doctoral scholarpractitioner," International J ournal of Organizational Behaviour, 7 (2), 375- 393.

Klein, H.K. and Rowe, F. 2008. "Marshalling the professional experience of doctoral students: a contribution to the practical relevance debate," MIS Quarterly, 32 (4), 675- 686.

Lester, S. 2004. "Conceptualizing the practitioner doctorate," Studies in Higher Education, 29 (6), pp.757-770.

Mahlberg, T. 2017. "Alter-Identity Work via Social Media in Professional Service Contexts." in Proceedings of the 28th Australasian Conference on Information Systems (ACIS 2017), Australasian Association for Information Systems, Hobart.

Manathunga, C., Pitt, R., Cox, L., Boreham, P., Mellick, G. and Lant, P. 2012. “Evaluating industry-based doctoral research programs: perspectives and outcomes of Australian Cooperative Research Centre graduates," Studies in Higher Education, vol. 37, no. 7, pp. 843-858.

Mathiassen, L. and Sandberg, A. 2013. "How a professionally qualified doctoral student bridged the practice-research gap: a confessional account of Collaborative Practice Research," European J ournal of Information Systems, 22, no. 4: 475-492.

Nicolini, D. 2012. Practice theory, work, and organization: An introduction, Oxford University Press.

Orlikowski, W.J . and Barley, S.R. 2001. "Technology and institutions: What can research on information technology and research on organizations learn from each other?," MIS Quarterly, 25(2), pp.145165.

Riemer, K., and J ohnston, R.B. 2017. “Clarifying Ontological Inseparability with Heidegger's Analysis of Equipment,” MIS Quarterly, (41:4), pp. 1059-1081.

Roberts, A.G. 2018. "Industry and $\mathrm{PhD}$ engagement programs: inspiring collaboration and driving knowledge exchange," Perspectives: Policy and Practice in Higher Education, pp.1-9. 
Smith, M.L., 2006. "Overcoming theory-practice inconsistencies: Critical realism and information systems research," Information and organization, 16(3), pp.191-211.

Stewart, R.A. and Chen, L., 2009. "Developing a framework for work integrated research higher degree studies in an Australian engineering context," European Journal of Engineering Education, 34(2), pp.155-169.

Turner, V. 1987. Betwixt and between: The liminal period in rites of passage, Betwixt and between: Patterns of masculine and feminine initiation, pp.3-19.

Van deVen, A.H. 2007. Engaged Scholarship: A Guidefor Organizational and Social Research. Oxford University Press, Oxford.

Van Gennep, A. 1909. The Rites of Passage, London: Routledge and Kegan Paul.

Weick, K.E. 1995. Sensemaking in organizations, Sage Publications, Michigan.

Westphal, J., and Khanna, P. 2003. "Keeping directors in line: Social distancing as a control mechanism in the corporate elite," Administrative Science Quarterly, 48: 3.

\section{Acknowledgements}

We wish to pay our respects to our dear colleague, friend and confidant, Natalie Hardwicke, who passed away suddenly and unexpectedly while this paper was under review. You are with us every day as we continue to experience this worldly existence. Thank you for sharing this journey.

\section{Copyright}

(c) 2018 Natalie Hardwicke, Tim Mahlberg \& Kai Riemer. This is an open-access articledistributed under the terms of the Creative Commons Attribution-Non Commercial 3.0 Australia License, which permits non-commercial use, distribution, and reproduction in any medium, provided the original author and ACIS are credited. 